\title{
Sterile mosquitoes near take-off
}

Malaysia is looking to battle dengue fever by releasing mosquitoes that have been genetically engineered to be sterile. Although these efforts have stirred public concern, the country's Academy of Sciences is likely to recommend the strategy to the government within a month.

In April, the Institute for Medical

Research in Kuala Lumpur indicated that it might release millions of male Aedes aegypti mosquitoes that have been genetically modified to produce offspring that die in the larval stage. The release of enough of the sterile males would theoretically swamp fertile wild-type competitors and crash the population.

This 'sterile insect technique' has been successful in the past, for example in eliminating the medfly from California and the parasitic screw worm from the United States and much of central America. But those insects were sterilized using radiation, which doesn't work as well on mosquitoes. Irradiated mosquitoes are unable to compete with wildtype males to mate with females.

Scientists in Malaysia have been working with mosquitoes created by Oxitec, a company based in Oxford, UK, and founded by University of Oxford geneticist Luke Alphey. Oxitec integrated a genetic element, LA 513, into the DNA of the mosquitoes. This genetic modification kills any offspring in the larval stage if they are not fed the drug tetracycline. In the lab, the mosquitoes are fed tetracycline and grow in the millions. In the wild, the modified gene kicks in, and, in theory, would be able to crash the local A. aegypti population (H. K. Phuc et al. BMC Biol. doi:10.1186/1741-7007-5-11;2007).

Between September and December of last year, the Institute for Medical Research, part of the Malaysian health ministry, evaluated Oxitec's RIDL-513A strain of A. aegypti in what Alphey describes as "the most realistic environment in which engineered mosquitoes have ever been tested". The engineered mosquitoes did well in competing with wild-type males, mating at the same rate with females. "That would certainly be a step forward over radiation," says Austin Burt of Imperial College London, who works on genetically modifying mosquitoes for malaria control.

Local environmentalists reacted with alarm to media reports last month that the strain would be released on Pulau Ketam, an island fishing village a few dozen kilometres from Kuala Lumpur. The next day, the government issued a press release saying, "Such a release will never be carried out without the proper clearance of the relevant authorities." Researchers from the Institute for Medical Research did not respond to requests for comment.

Gurmit Singh, an environmentalist and chairman of the non-profit Centre for Environment, Technology and Development in Petaling Jaya, says the main problem is that the government never made public details of the long-term potential for ecological disturbance. "How are the mosquitoes produced, and what's the possibility that the mutation could spread?" Singh asks.

Burt notes that people shouldn't be worried because the mosquitoes are designed to die out rather than spread. In his unrelated work, Burt is trying to modify genes to make it difficult for mosquitoes to pass malaria to humans. Unlike Oxitec's mosquitoes, Burt's would need to have a selective advantage for the gene to spread. Burt says that changing the gene pool is "not something you do lightly", but that he hopes to have a mosquito ready for trials in the next five years. Burt's project has, like Alphey's, received money from the Bill \& Melinda Gates Foundation, which lists as one of its Grand Challenges for Global Health: "Develop a genetic strategy to deplete or incapacitate a diseasetransmitting insect population."

Malaysia's field trials could go ahead long before Burt's. Alphey met with the Malayasian Academy of Sciences on 16 May and says the meeting went well; C. P. Ramachandran, who chairs the relevant committee and has decades of experience in tropical disease research, said "the science is excellent". He adds that, "any risks related to genetically modified organisms must be balanced against the potential benefits," noting that Malaysia has tens of thousands of dengue cases each year.

According to the World Health Organization, spread of dengue since the 1970 s has put 2.5 billion people at risk, with an estimated 50 million cases each year. David Cyranoski
ON THE RECORD

(CThe word God is for me nothing more than the expression and product of human weaknesses.")

Albert Einstein, in a 1954 letter that sold last week at auction in London for $€ 170,000$. Richard Dawkins was one of the losing bidders.

\section{SCORECARD}

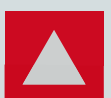

Engineering for artists Engineers say they have worked out

how to safely reconstruct Henry Moore's giant 1980 sculpture Arch, which was dismantled in 1996 after cracks started to appear. It needs better bolting and firmer foundations, they say - although they haven't worked out the details yet.

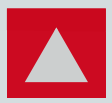

Art for engineers The Habog nuclearwaste storage facility

has been prettied up by artist William Verstraeten, who painted it orange, with $\mathrm{E}=\mathrm{mc}^{2}$ and $\mathrm{E}=\mathrm{h} v$ written along the side. The artist says he chose orange because it's halfway between

red-for-danger and green-for-safety.
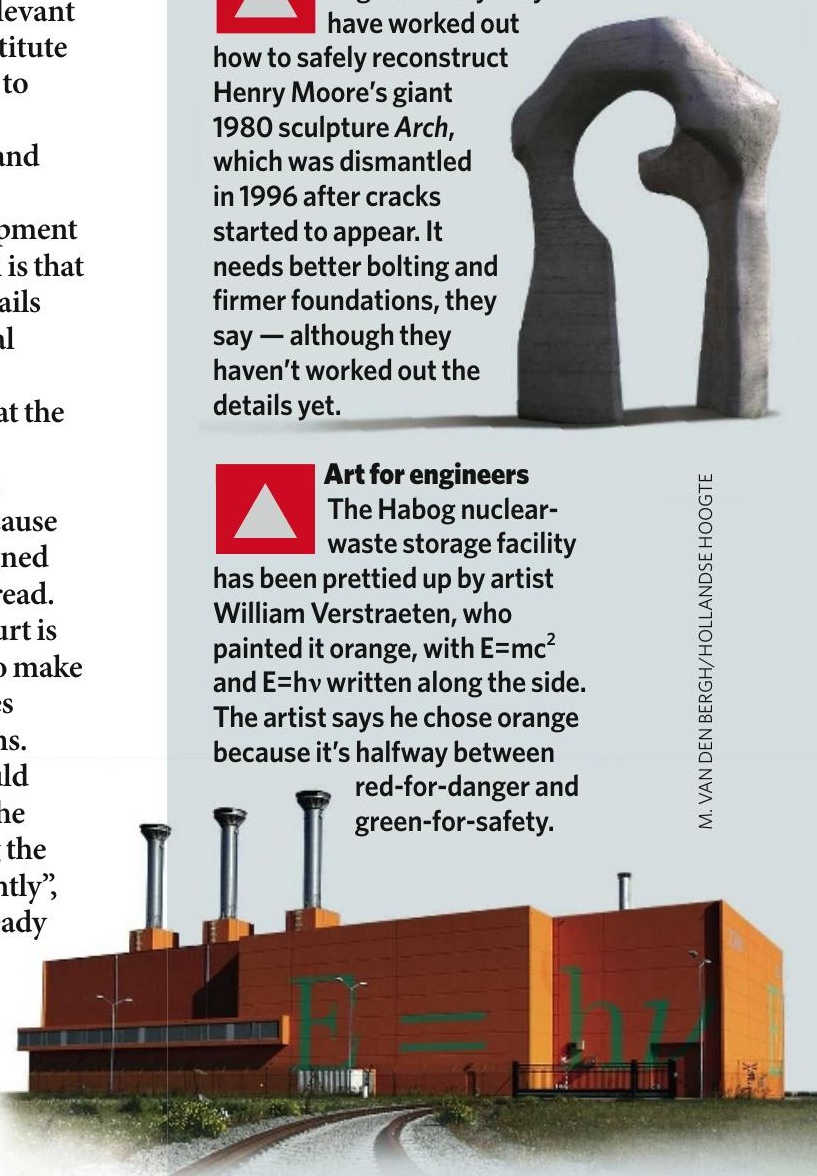

ZOO NEWS

Returned from the choir invisible

The fossil of a 55-million-yearold parrot has been found in Denmark. Officially named Mopsitta tanta, it will forever be known as a 'Norwegian Blue' (despite there being no evidence of its colour) after Monty Python's parrot sketch. This one, too, is clearly dead, but not "pining for the fjords" - Norway didn't get its fjords until more than $\mathbf{5 0}$ million years later.

Sources: UPI, Imperial College London, World Nuclear News, AlphaGalileo 